Short report

\title{
Phenotypic expression of the first liveborn 68,XX triploid newborn
}

\author{
Paul Merlob, Nora Naor, Mordechai Shohat
}

Triploidy is a common numerical chromosomal anomaly in spontaneous first trimester abortions, ${ }^{1}$ but only $5.5 \%$ of all triploidies are associated with another chromosome anomaly. ${ }^{1}$ Among these double aneuploidies very few patients with a $68, \mathrm{XX}$ chromosome constitution have been reported. ${ }^{12}$ Recently, Kaffe et $a l^{3}$ described for the first time the features observed at necropsy of a 21 week old fetus with $68, \mathrm{XX}$ triploidy. We wish to report the phenotypic expression of the first patient with this chromosomal aberration who was born at term and lived for six days.

The proband was delivered at 39 weeks' gestation after an uncomplicated pregnancy to a 32 year old gravida 10, para 8 mother. The parents were healthy and unrelated. Their seven previous children were normal.

Physical examination showed a small for dates infant, birth weight $2000 \mathrm{~g}$, length $44.5 \mathrm{~cm}$, and head circumference $31 \mathrm{~cm}$. The head was microcephalic with a large posterior fontanelle and fuzzy hair. The ears were small $(2.5 \mathrm{~cm}$, well below $-2 \mathrm{SD})$ with bilateral unfolded helices and small tragi. The eyes showed proptosis with shallow supraorbital regions. The inner canthal distance $(1.7 \mathrm{~cm})$ was -2 SD from the mean (borderline hypotelorism). Bilateral vertically ovoid corneae and coloboma of the left iris including the optic nerve were observed. There was dilatation of the right pupil of only 3 to $4 \mathrm{~mm}$ and a depressed nasal bridge, left deviation of the nasal septum, and a prominent columella were evident. The mouth was small (intercommissural distance $1.9 \mathrm{~cm},<-2 \mathrm{SD})$ with a short philtrum $(0.7 \mathrm{~cm},<-2 \mathrm{SD})$, posterior cleft palate, and limited

Department of Neonatology and the Genetic Institute, Beilinson Medical Centre, Sackler School of Medicine, Tel Aviv University, Petah Tiqva 49100, Israel.

P Merlob, N Naor, M Shohat

Correspondence to Professor Merlob.

Received for publication 26 February 1991.

Revised version accepted for publication 18 April 1991. opening. The internipple distance was normal $(7.5 \mathrm{~cm})$, but the nipples were flat and low set.

The hands showed ulnar deviation with low insertion of small thumbs, fusiform digits, small first phalanges, and bilateral simian creases. The feet were large with prominent heels. There was bilateral partial cutaneous syndactyly between toes 2 and 3, bilateral clinodactyly of the fifth toe, and a large hallux with an unusual, dome-like shape. There was a prominent clitoris not covered by labia majora and absence of the fourchette. A systolic murmur 1 to $2 / 6$ was heard at the lower sternal border and echocardiography indicated persistent fetal circulation (PFC). Brain ultrasound was normal. The infant died at the age of 6 days after repeated cardiac arrests, secondary to Listeria sepsis and PFC.

$\mathrm{G}$ banded chromosome analysis of 25 bone marrow cells showed an abnormal karyotype with 68 chromosomes in each cell. All cells showed an extra set of autosomes with only two sex chromosomes, $68, \mathrm{XX}$ (figure). The diagnosis was subsequently confirmed on skin fibroblast culture.

Double aneuploidy, 68, XX triploidy, is a very rare numerical chromosomal aberration. Only eight cases have been reported previously and seven of these were observed in early spontaneous abortuses. ${ }^{124}$ The eighth case, recently described by Kaffe et $a l,{ }^{3}$ was a 21 week old fetus. Therefore, to the best of our knowledge, our patient is the first liveborn infant with $68, \mathrm{XX}$ triploidy.

The phenotypic abnormalities of the present patient are similar in many ways to those seen in complete and mosaic triploidy but there are some important differences. The most striking differences were in the ears, eyes, hair, and genitalia. The present patient had type I microtia but not low set, malformed, or posteriorly rotated ears as in triploidy. However, she had hypotelorism. Another unusual anomaly was fuzzy hair, but perhaps the most distinctive defects of $68, \mathrm{XX}$ triploidy were present in the female genitalia. All previously described females with complete or mosaic triploidy had normal external genitalia, in spite of numerous anomalies observed in male external genitalia. Many more observations of females with $68, \mathrm{XX}$ triploidy 


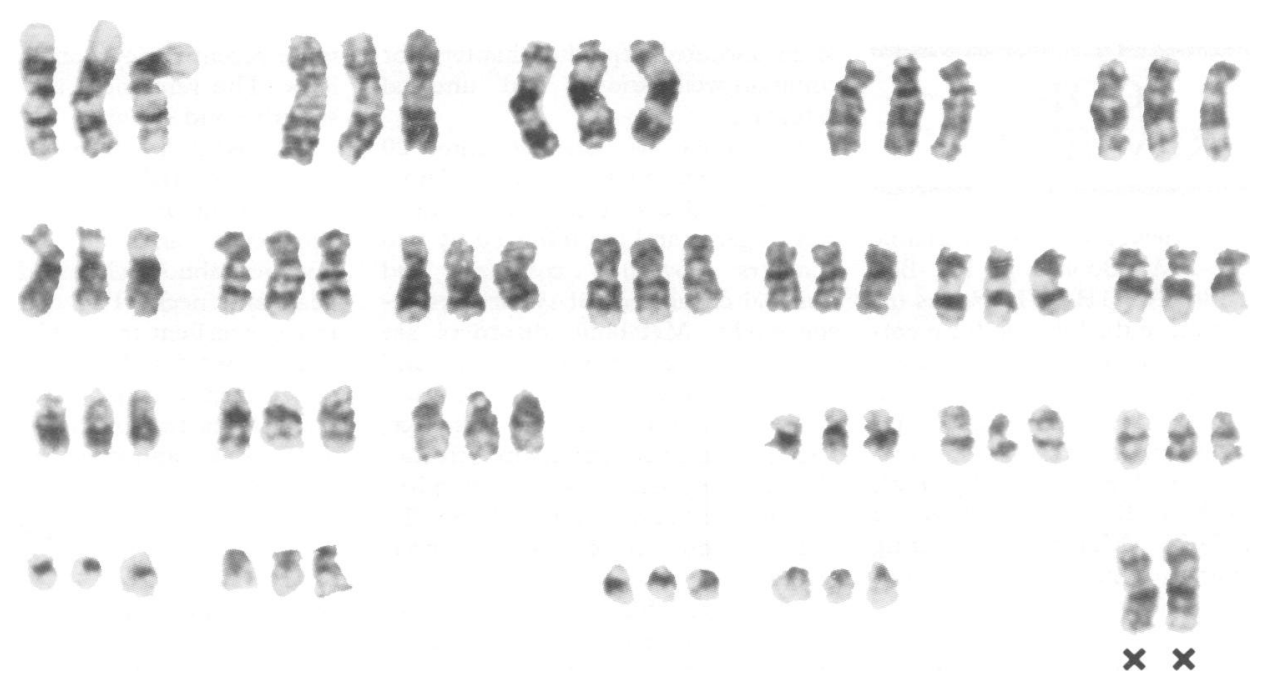

The karyotype of the proband $(68, X X)$.

are needed to define the clinical picture, but the presence of anomalies of the female external genitalia in an infant with signs of triploidy might suggest the possibility of this double aneuploidy $(68, \mathrm{XX})$.

Of interest are the phenotypic differences between our infant and the recently described patient of Kaffe et $a .^{3}$ The dysmorphic facial features observed in their 21 week old fetus (hypoplastic mandible, broad nasal bridge, long philtrum, and low set ears) were not encountered in our patient. This may raise the question of the possible changes in dysmorphic features during intrauterine life (from 21 to 39 weeks' gestation).

1 Boue A, Boue J, Gropp A. Cytogenetics of pregnancy wastage. Adv Hum Genet 1985;14:1-57.

2 Uchida IA, Freeman VCP. Triploidy and chromosomes. $\mathrm{Am} \mathrm{f}$ Obstet Gynecol 1985;151:65-9.

3 Kaffe S, Eliasen C, Wan L. A rare case of $68, \mathrm{XX}$ triploidy diagnosed by amniocentesis. Prenat Diagn 1989;9;857-61.

4 Jacobs PA, Szulman AE, Funkhouser J, et al. Human triploidy: relationship between parental origin of the additional haploid complement and development of partial hydatidiform mole. Ann Hum Genet 1982;46:223-31. 